\title{
PENETRÔMETRO DE CONE COM TAXA CONSTANTE DE PENETRAÇÃO NO SOLO: DESENVOLVIMENTO E TESTE DE FUNCIONALIDADE
}

\section{DALVAN J. REINERT ${ }^{1}$, GILBERTO L. COLLARES ${ }^{2}$, JOSÉ M. REICHERT ${ }^{1}$}

\begin{abstract}
RESUMO: Penetrômetros auxiliam na determinação da capacidade de suporte do solo na engenharia civil e na avaliação da resistência mecânica de solos agrícolas, relacionando-a com compactação do solo e crescimento do sistema radicular das plantas. Este trabalho relata o desenvolvimento de um penetrômetro de cone com taxa constante de penetração, suas partes e funcionalidade, bem como resultados do uso na avaliação comparativa da compactação em experimentos e em lavoura. A quantificação da resistência é realizada com célula de carga, a distância de penetração no solo com potenciômetro, e a aquisição e o armazenamento de dados com placas eletrônicas. A concepção do equipamento, que emprega velocidade constante de penetração da haste no perfil do solo, possibilitou a aquisição de grande coleção de dados relativos com pequena variação de profundidade $(5 \mathrm{~mm})$, atingindo a profundidade máxima de $0,80 \mathrm{~m}$. $\mathrm{O}$ equipamento é eficaz na aquisição e no tratamento de dados de resistência mecânica do solo à penetração em profundidade do perfil. A variação entre os pontos permite inferir sobre parâmetros e características do solo, bem como sobre o comportamento desses sob condições externas impostas, quer seja imediata, quer seja residual.
\end{abstract}

PALAVRAS-CHAVE: penetrometria, resistência mecânica, compactação do solo.

\section{CONSTANT-RATE CONE PENETROMETER: DEVELOPMENT AND FUNCTIONALITY}

\begin{abstract}
Penetrometers are used to quantify soil bearing capacity in civil engineering and to evaluate mechanical resistance of agricultural soils, which is an indicator of soil compaction and of root growth. This paper reports the development, components and functionality of a constant-rate cone penetrometer, as well as its application to measure soil compaction. The force is measured by a load cell, the distance is measured by a potentiometer, and data acquisition and storage are performed by an electronic board. The equipment was tested in agricultural field transects with profile variability and experimental plots with compaction variability, generating soil penetration resistance information with a resolution of $5 \mathrm{~mm}$, from the soil surface down to a depth of $0.8 \mathrm{~m}$. The equipment showed good performance in its usage and data acquisition and storage of soil resistance. The data clearly show how the soil penetration resistance changes in depth and with soil compaction state, paving the way to study soil horizons distribution and immediate and residual compaction.
\end{abstract}

KEYWORDS: penetrometer, mechanical resistance, soil compaction.

\section{INTRODUÇÃO}

Penetrômetros portáteis de acionamento manual têm sido e serão usados para medir a resistência do solo à penetração, a qual está relacionada a importantes atributos do solo e das plantas. Um aspecto associado ao uso desses aparelhos relaciona-se à influência do operador nos resultados obtidos, particularmente pela dificuldade em manter-se uma taxa constante de penetração. A limitação ao uso mais extensivo de equipamentos existentes com velocidade constante de penetração e armazenamento eletrônico de dados, por sua vez, está no alto custo e nas

\footnotetext{
${ }^{1}$ Prof. Doutor, Departamento de Solos, UFSM, Santa Maria - RS, Fone: (0XX55) 3220.8108, dalvan@ccr.ufsm.br, reichert@smail.ufsm.br

${ }^{2}$ Prof. Doutor, Conjunto Agrotécnico Visconde da Graça, UFPEL, Pelotas - RS, gilbertocollares@ brturbo.com.br Recebido pelo Conselho Editorial em: 12-12-2005
}

Aprovado pelo Conselho Editorial em: 19-3-2007 
dificuldades de importação, uma vez que não existem equipamentos similares de fabricação nacional.

Quando o solo é comprimido, sua densidade aumenta, e a porosidade total diminui, com redução no volume de macroporos e incremento no volume de microporos. Com a compactação, reduz-se a aeração e a disponibilidade de água e de nutrientes às plantas e aumenta o impedimento mecânico ao crescimento radicular (LETEY, 1985). Alguns estudos abordam o tema com o conceito da faixa ótima de umidade do solo, na qual as plantas exibem mínimas limitações ao crescimento e desenvolvimento, quanto à disponibilidade de ar, de água e de resistência do solo (SILVA et al., 1994; KLEIN \& LIBARDI, 2000; REINERT et al., 2001b). Outros autores defendem um conceito mais simples de valores de propriedades físicas, especialmente a densidade e a resistência do solo à penetração, em que o sistema radicular das plantas não penetra quando os valores observados forem maiores do que os críticos (TAYLOR \& GARDNER, 1963; TAYLOR et al., 1966; REINERT et al., 2001a; THOMPSON et al., 1987).

A aplicação e os tipos de penetrômetros variam muito, especialmente nas várias estratégias utilizadas nas montagens dos equipamentos (BRADFORD, 1986; PERUMPRAL, 1987; LOWERY \& MORRISON, 2002), mas seguindo as especificações do cone e da velocidade de penetração apresentadas pela Sociedade Americana de Engenharia Agrícola (ASAE, 1999).

A maioria dos penetrômetros usados em estudos de manejo do solo emprega a força manual para a penetração da haste do equipamento, o que causa grande variabilidade devido à dificuldade de impor pressão constante ao longo do tempo de penetração, tal que permita velocidade constante durante todo o procedimento de penetração, especialmente quando há variação do estado de compactação do solo com o aprofundamento no perfil do solo. Para obter velocidade uniforme de penetração, alguns pesquisadores (BRADFORD, 1986; PERUMPRAL, 1987; ROONEY \& LOWERY, 2000; WILFORD et al., 1972; ARRIAGA et al., 2002) adaptaram o penetrômetro ao sistema hidráulico de tratores ou de motores adaptados em veículos utilitários, usando a força hidráulica para imprimir velocidade de penetração aproximadamente constante. Esses sistemas têm a desvantagem de causarem efeito do tráfego pelo veículo nas áreas experimentais, muitas vezes com acesso restrito, sendo mais recomendados para outros usos que não a avaliação comparativa da compactação em sistemas de manejo de solo.

Para reduzir o tamanho e facilitar o uso em parcelas experimentais durante todo o ciclo de culturas agrícolas comerciais, LOWERY (1986) desenvolveu um penetrômetro de cone montado num tripé, equipado com célula de carga para medir a força, com identificador de profundidade e com a penetração uniforme impulsionada por motor elétrico movido a bateria. O modelo foi modificado posteriormente por SCHULER \& LOWERY (1987), acoplando o sistema a um carrinho e com autonivelamento da mesa que sustenta a haste com o cone, e por LARNEY et al. (1989), adicionando um dispositivo computadorizado para aquisição, interpretação e armazenamento dos dados. Posteriormente, com a disponibilidade de modernos leitores e armazenadores de dados, esses também puderam ser utilizados no mesmo equipamento.

Atualmente, estão disponíveis no mercado modernos e acurados dispositivos eletrônicos de medição e estimativa de força (células de carga) e distância (potenciômetro, por exemplo), assim como disponibilidade de tecnologia para montagem de placas eletrônicas de aquisição, interpretação e armazenamento de dados, prescindindo de computadores convencionais (PCs), reduzindo-se os custos dos equipamentos e aumentando a funcionalidade e a robustez de sistemas dedicados como um penetrômetro.

Este trabalho relata o desenvolvimento de um penetrômetro de cone com taxa constante de penetração, suas partes e funcionalidade, bem como os resultados do uso com o objetivo de avaliar comparativamente a compactação do solo. 


\section{MATERIAL E MÉTODOS}

\section{Desenvolvimento e características do penetrômetro}

O equipamento foi montado em uma estrutura metálica quadrada, de 0,60 m de lado, com 1,5 m de altura, construída em tubo de alumínio retangular, dotado de dispositivo lateral para suporte de braços retráteis para o transporte manual (Figura 1). O sistema de penetração foi disposto em dois planos estruturais sustentados no corpo do equipamento por meio de mecanismo composto de mancais e rolamentos que permitem o nivelamento desses planos em duas direções, proporcionando penetração na vertical, mesmo em terreno inclinado.

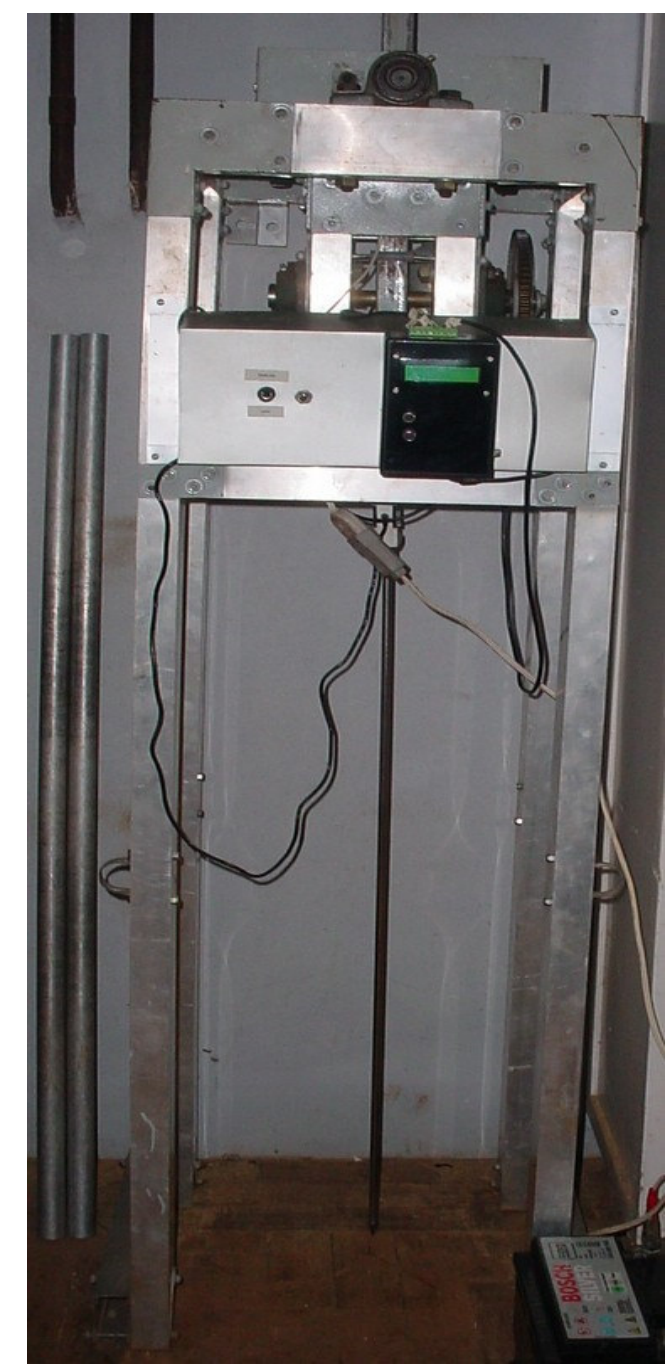

FIGURA 1. Vista geral do penetrômetro desenvolvido.

O sistema de penetração consta de haste dentada tipo "cremalheira" ligada à haste do penetrômetro pela célula de carga. A célula de carga empregada, marca Kratos, tem capacidade limite de $2500 \mathrm{~N}$ e mede a força aplicada ao cone, transmitindo sinais elétricos em $\mathrm{mV}$ a um sistema de aquisição de dados. A haste do penetrômetro foi confeccionada em perfil de aço inoxidável redondo de $10 \mathrm{~mm}$ de diâmetro e $100 \mathrm{~cm}$ de comprimento. A ponteira cônica de aço inoxidável, fixada na extremidade inferior da haste de penetração, tem área basal de $129 \mathrm{~mm}^{2}$, diâmetro da base de $12 \mathrm{~mm}$ e ângulo de $30^{\circ}$.

O sistema eletromecânico é dotado de motor elétrico, alimentado por bateria de 12 V/56 A, que aciona um conjunto de engrenagens, responsável pela transmissão do movimento vertical à haste de penetração. Uma chave seletora manual possibilita que o operador controle o movimento da haste de penetração em três distintas direções, quais sejam: desligado, ascendente e descendente. 
O mecanismo de acionamento e transmissão foi projetado para atingir a velocidade de penetração constante, similar à recomendada pela ASAE (1999). O motor utilizado é um motorredutor da marca BOSCH, DHP 12 VCC. A estrutura, as hastes e os cones foram confeccionados pelo Núcleo de Automação e Fabricação (NAFA) do Centro de Tecnologia da UFSM.

A profundidade de penetração é obtida por intermédio de um transdutor constituído por um potenciômetro de filamento de aço revestido com náilon ("string potentiometer"), marca Unimeasure e modelo LX-PA-50 (UNIMEASURE, 2007), com comprimento do filamento podendo atingir $1.250 \mathrm{~mm}$ de distância e com variação de saída de sinais elétricos 0 a $2.500 \mathrm{mV}$. Esse é um componente de resistência variável, sendo seu funcionamento orientado pela variação de deslocamento a partir da extremidade do filamento conectado na parte inferior da haste dentada do sistema de penetração. Com o início do processo de penetração, ocorre deslocamento, e o componente, que recebe a tensão constante $(12 \mathrm{~V})$, varia a resistência, produzindo diferença de potencial em conformidade com a resistência imposta ao deslocamento, transferindo os sinais elétricos, em mV, para o sistema de aquisição de dados.

O sistema de aquisição, cálculo e armazenamento de dados foi desenvolvido pela JP Tecnológica. Os componentes do "datalogger" são: (1) placa principal, baseada nos seguintes componentes semicondutores: microcontrolador Microchip PIC16F877 (processador RISC de 8 Bits com conversores A/D de 10 Bits); interface RS-232 Maxim MAX232 e regulador de tensão National LM2936Z-5.0; (2) placa de interface, baseada nos seguintes componentes semicondutores: amplificadores de instrumentação Texas Instruments INA114, amplificadores operacionais Intersil CA3140 e proteção das entradas com diodo zener 5,1 V; (3) monitor de cristal líquido, 16 caracteres $\mathrm{x}$ duas linhas, e (4) placa externa com memória EEPROM Catalyst CAT24C256 (32 kbytes).

Os circuitos de condicionamento de sinal são mostrados nas Figuras 2 e 3 . O sistema consta de: (1) placa de aquisição de dados que coleta simultaneamente os sinais elétricos da célula de carga e do potenciômetro, descritos anteriormente; (2) "chip" com "software" que converte a saída elétrica, da célula de carga e do potenciômetro, em unidades de pressão e profundidade; (3) memória externa de 60 Mbytes que armazena os pares de dados de pressão e profundidade, e (4) "software" para transferir os dados da memória para um computador. Os dados são criados em modo ASCII, podendo ser lidos por outros "softwares".

O "software" incluído no "chip" foi escrito em linguagem Assembly, seguindo o fluxograma apresentado na Figura 4, e desenhado de maneira que o sistema de aquisição desempenhe as seguintes funções (Figura 5): (1) inicia a coleta de dados somente a partir da leitura de pressão, quando a ponta do cone toca no solo; (2) executa a leitura dos sinais da célula de carga para incrementos de $\mathrm{mV}$ no potenciômetro correspondentes a cada incremento de $5 \mathrm{~mm}$ de deslocamento no filamento. Para isso desenvolveu-se calibração entre dados de saída da célula de carga, em mV, induzindo esforços variáveis de 0 a 200 N. Desse modo, os dados de resistência do solo à penetração são coletados para as profundidades definidas pelo deslocamento real, mesmo quando ocorrem pequenas variações de velocidade de penetração; (3) termina a coleta de dados, quando o valor de pressão for igual ou inferior aos observados com o penetrômetro em descanso. 


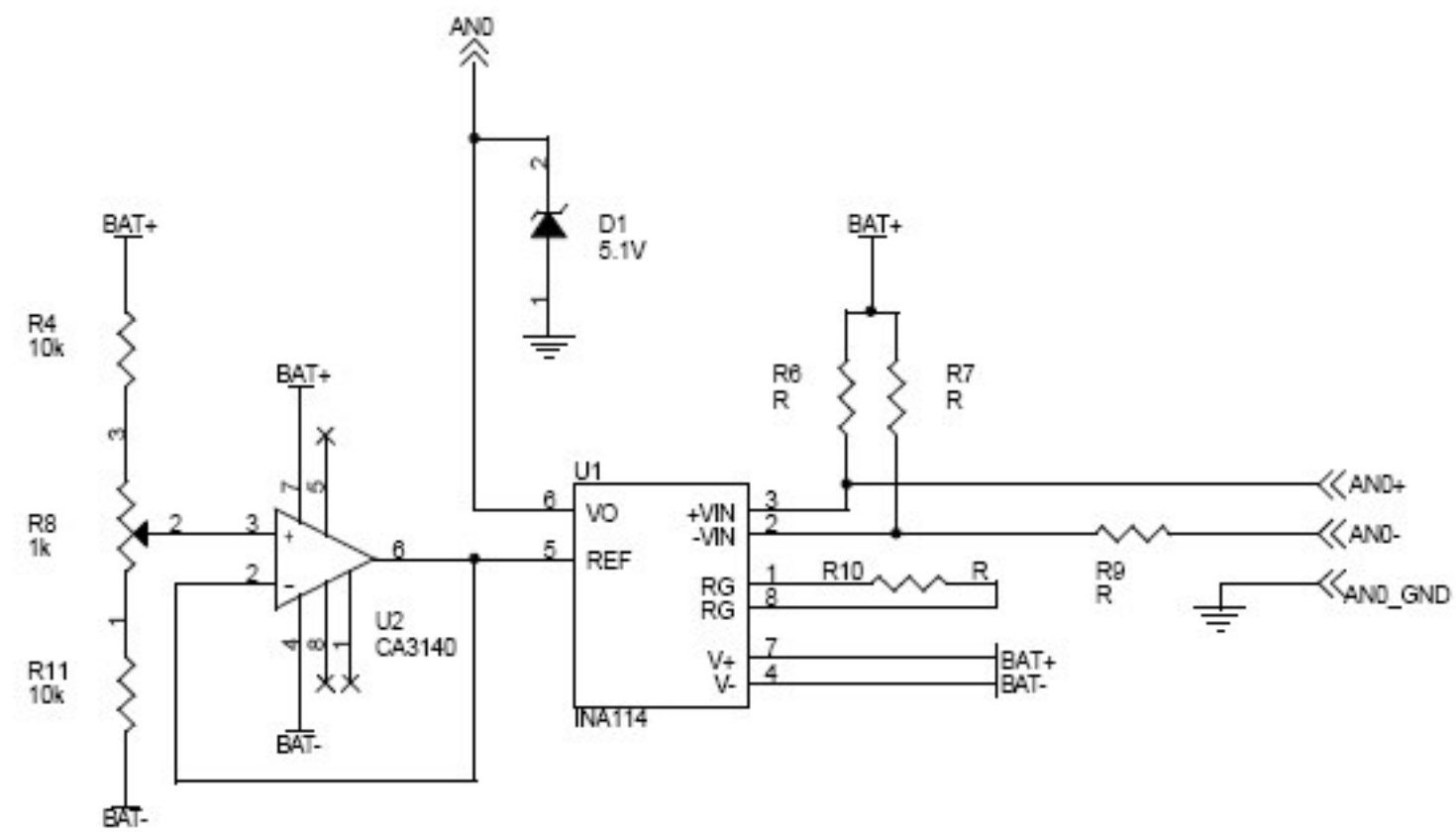

FIGURA 2. Entrada analógica para o potenciômetro indicador de profundidade.

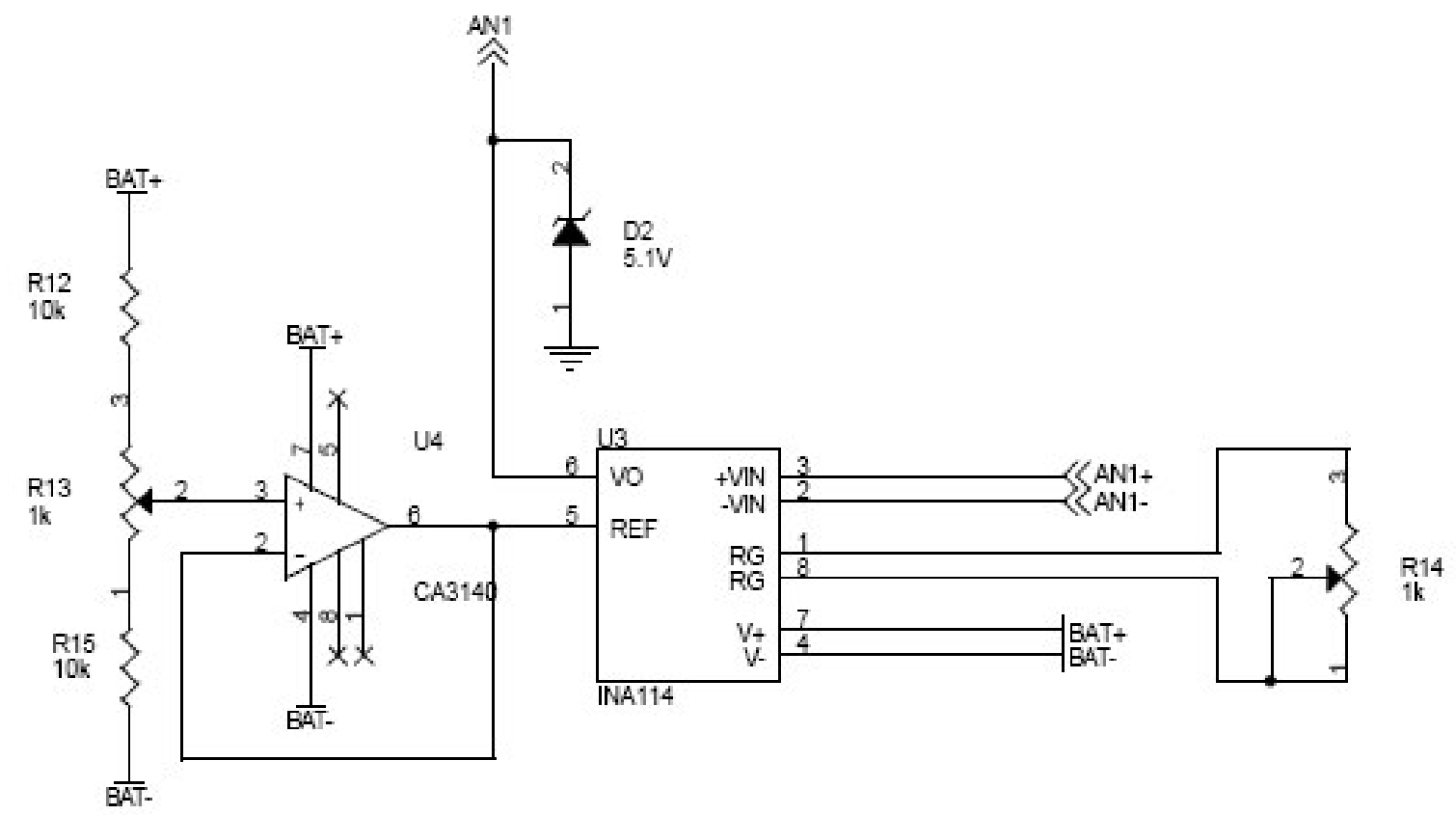

FIGURA 3. Entrada analógica para a célula de carga (resistência à penetração). 


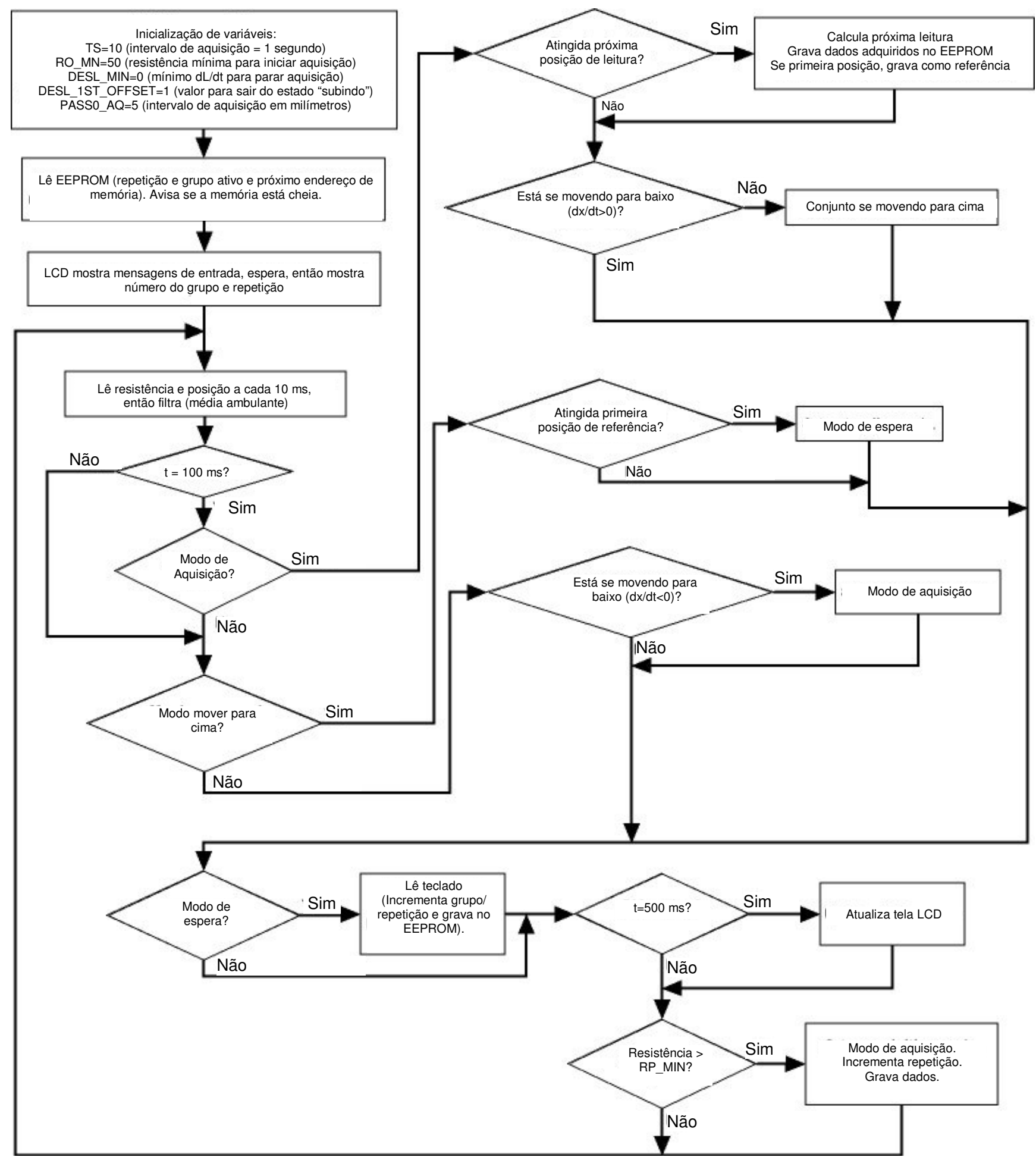

FIGURA 4. Fluxograma da rotina para aquisição, cálculo e armazenamento de dados do penetrômetro. 


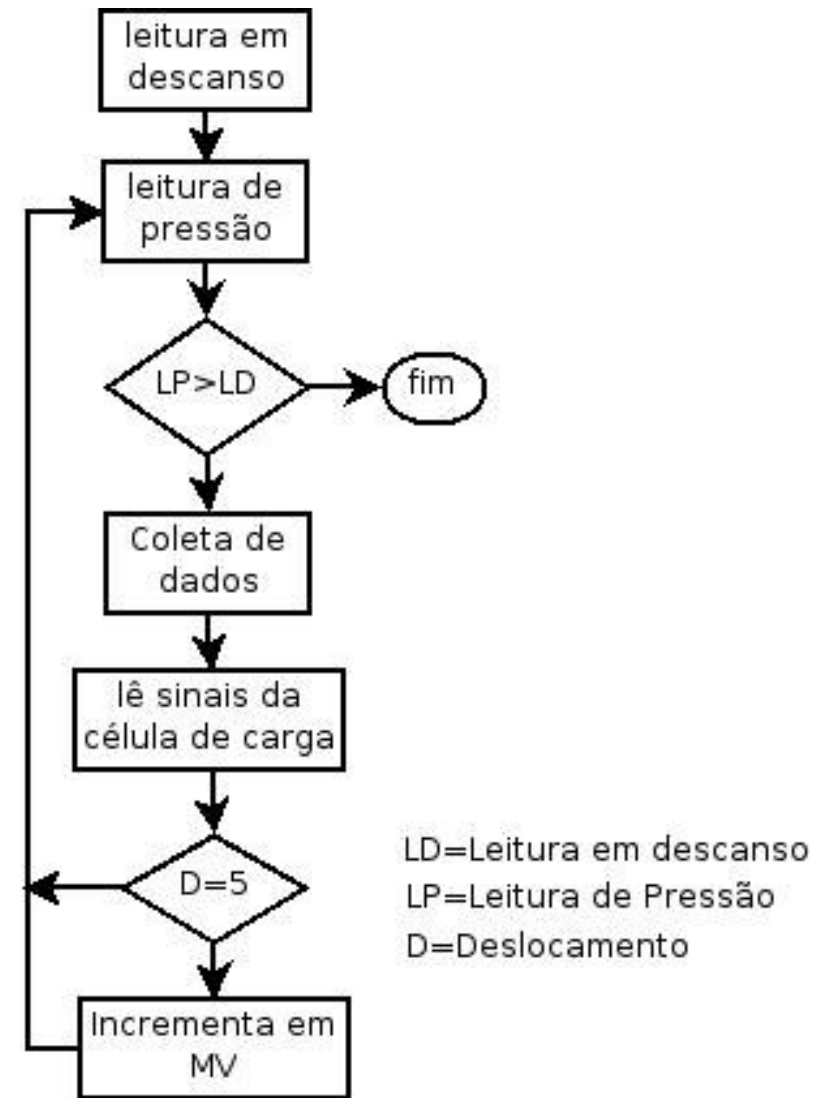

FIGURA 5. Funções desempenhadas pelo sistema de aquisição de dados do penetrômetro.

\section{Teste de funcionalidade do penetrômetro}

O equipamento desenvolvido foi testado na área experimental do Departamento de Solos do Centro de Ciências Rurais, localizado no Câmpus da Universidade Federal de Santa Maria, em Santa Maria - RS. O solo do local é classificado como Argissolo Vermelho distrófico arênico, com textura superficial arenosa, pertencente à Unidade de Mapeamento São Pedro.

O solo possui espessura do horizonte A variável, dependendo da localização na paisagem, observando-se ausência ou presença de horizonte E. Em área cultivada desde 1989 em sistema plantio direto, com sucessão de culturas de aveia no inverno e milho ou soja no verão, foram realizados testes que consistiram na realização de uma seqüência de 12 medidas de resistência à penetração, a cada $10 \mathrm{~m}$, em três faixas distintas entre terraços da área experimental, conforme descrição de ALBUQUERQUE et al. (1996). Medidas de resistência à penetração foram feitas também em um experimento desenvolvido para avaliar o processo de compactação do solo causado por tráfego de máquina de dez toneladas na superfície do solo, induzindo diferentes níveis de compactação (STRECK et al., 2004).

\section{RESULTADOS E DISCUSSÃO}

A concepção do equipamento, que emprega velocidade constante de penetração da haste no perfil do solo, possibilitou a aquisição de grande coleção de dados relativos à pequena variação de profundidade, de modo que se pode obter maior detalhamento aos resultados obtidos.

A variabilidade espacial da resistência à penetração $(\mathrm{RP})$ existente entre as faixas nos três transetos é apresentada nas Figuras 6 a 8. Na área com espessura de horizonte variável, as curvas de resistência à penetração da faixa 3 (Figura 6) apresentaram valor máximo na camada compreendida entre 8 e $13 \mathrm{~cm}$. Essa condição foi imposta pelo tráfego continuado ao longo do tempo, promovendo uma zona compactada nessa camada. Na faixa 4 (Figura 7), a máxima RP também atingiu valores máximos na camada entre 7 e $13 \mathrm{~cm}$; nos pontos 1 e 2, verificou-se RP acima de $6 \mathrm{MPa}$, respectivamente, nas profundidades de 17 e $27 \mathrm{~cm}$, podendo estar relacionada à 
presença de concreções, próprias desse Argissolo. Na faixa 5 (Figura 8), os máximos valores de RP estão a profundidades maiores, confirmando ser essa faixa com horizonte A profundo, como caracterizado por ALBUQUERQUE et al. (1996), e as pressões foram transmitidas para camadas mais profundas.
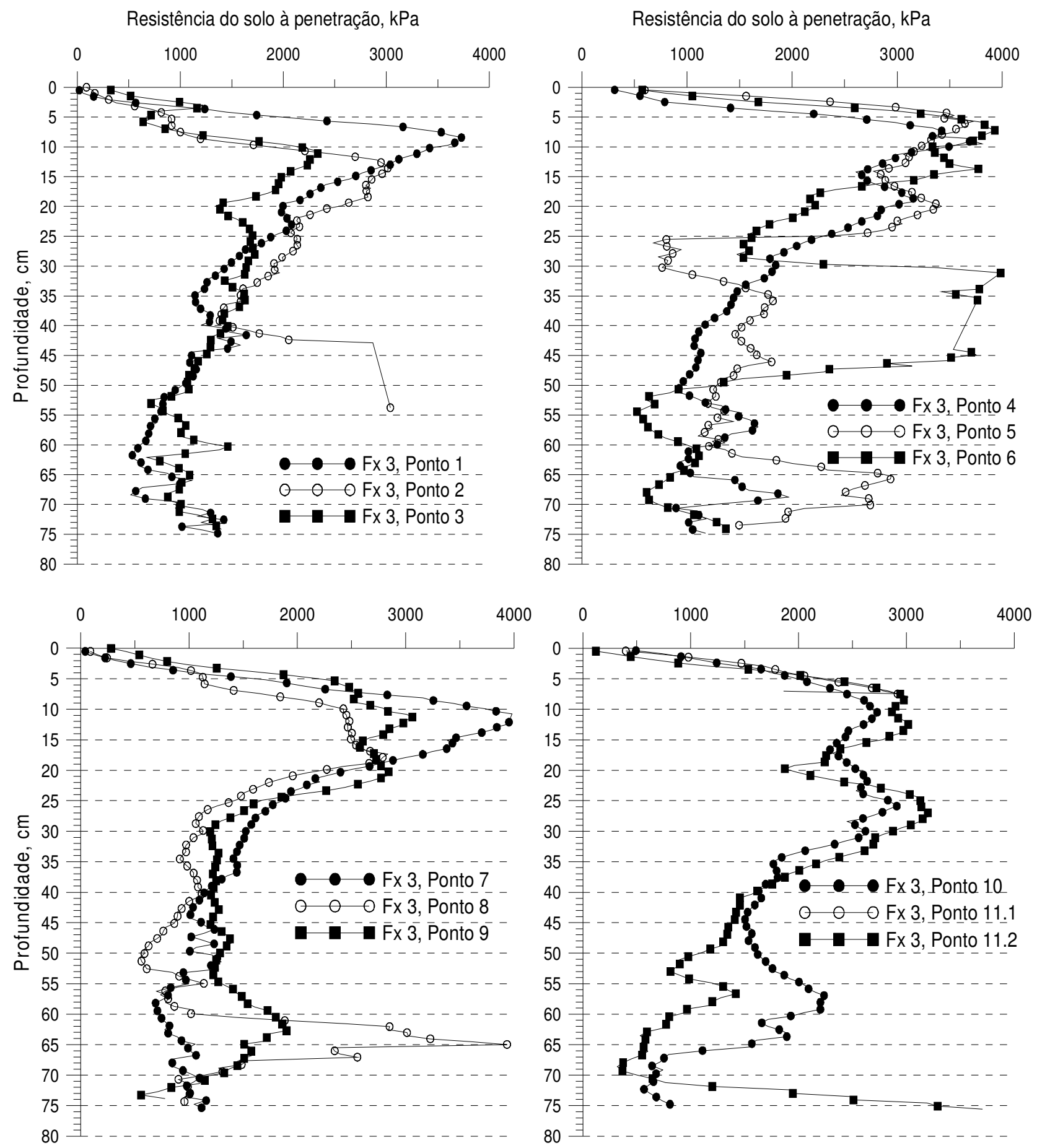

FIGURA 6. Variação da resistência à penetração em profundidade avaliada em distintos pontos, na faixa 3, definida por ALBUQUERQUE et al. (1996). 
Resistência do solo à penetração, $\mathrm{kPa}$

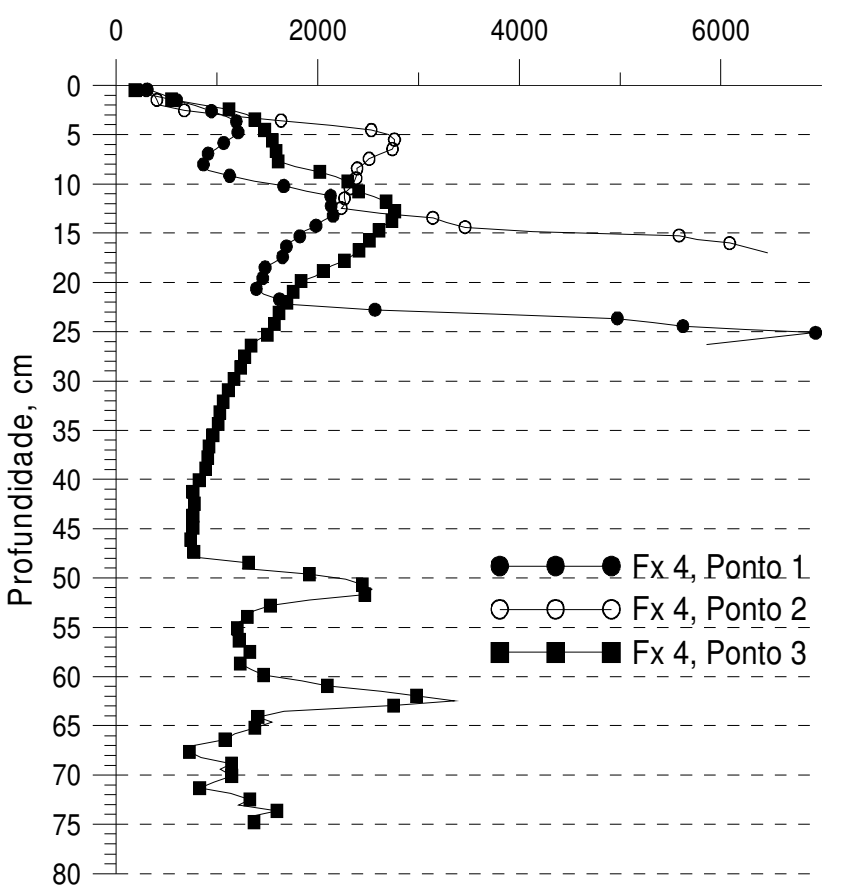

Resistência do solo à penetração, $\mathrm{kPa}$
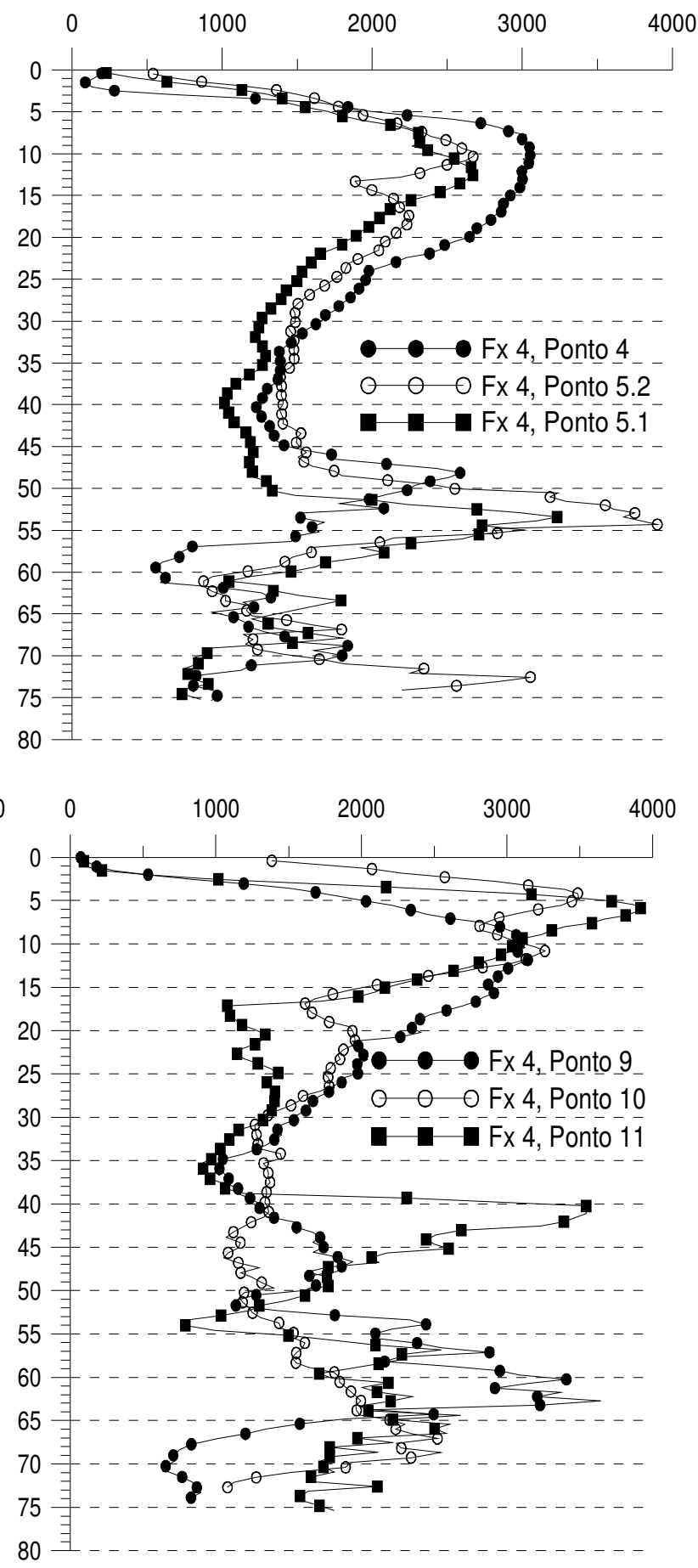

FIGURA 7. Variação da resistência à penetração em profundidade avaliada em distintos pontos, na faixa 4, definida por ALBUQUERQUE et al. (1996). 

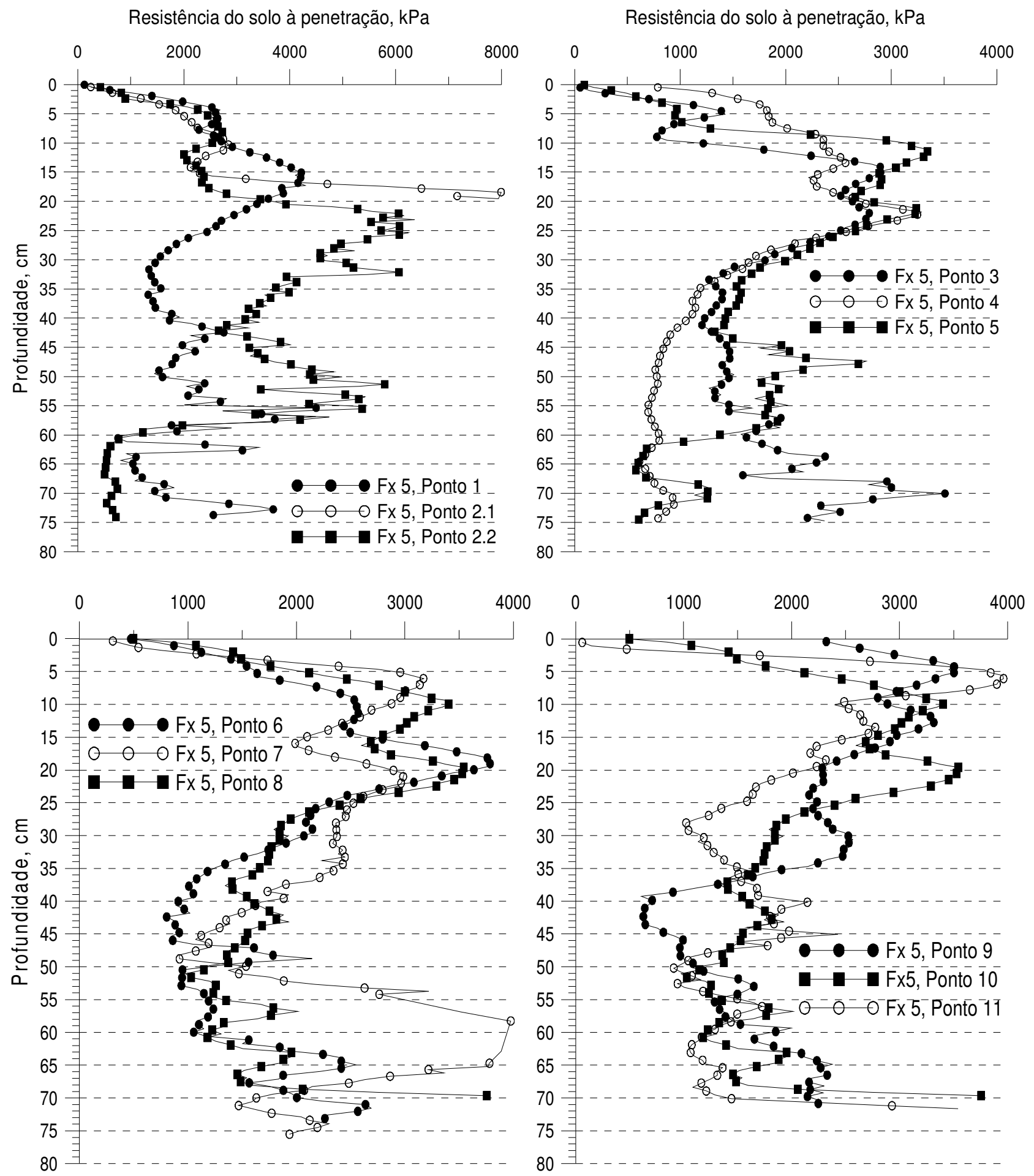

FIGURA 8. Variação da resistência à penetração em profundidade avaliada em distintos pontos, na faixa 5, definida por ALBUQUERQUE et al. (1996).

Na profundidade próxima aos $45-50 \mathrm{~cm}$, de maneira geral, a resistência sofreu acréscimo acentuado, podendo estar relacionada com a transição entre o horizonte $\mathrm{E}$ e $\mathrm{B}$, onde há presença significativa de concreções. Assim, o equipamento também permite identificar horizontes do solo até a profundidade de $80 \mathrm{~cm}$, o que é bastante útil para o mapeamento de solos na agricultura de precisão.

$\mathrm{Na}$ avaliação dos distintos níveis de compactação, adicional ou residual (Figura 9), o desempenho do equipamento também foi satisfatório, confirmando os resultados de STRECK et al. (2004), utilizando penetrômetro digital portátil Remik CP 20, com haste e ponta cônica de mesmas dimensões das empregadas no equipamento testado. 


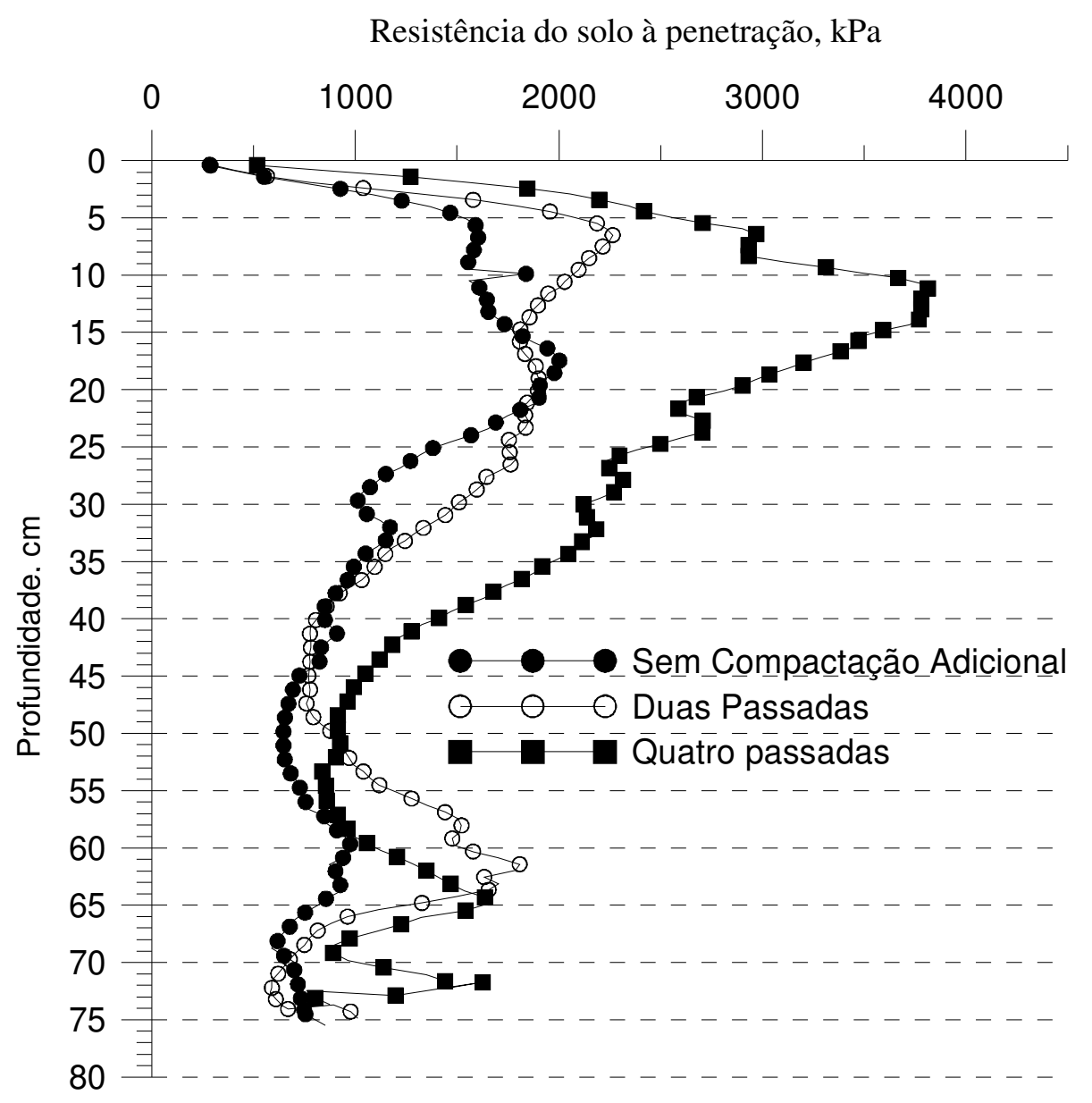

FIGURA 9. Variação da resistência à penetração em profundidade, em experimento com níveis de compactação, adicional ou residual, estabelecidos por STRECK et al. (2004).

Com base nas medidas do penetrômetro desenvolvido, na camada de 7 a $40 \mathrm{~cm}$, o tratamento que recebeu compactação adicional promovida por quatro passadas de máquina de dez toneladas, teve superioridade na resistência de, no mínimo, $500 \mathrm{kPa}$ em relação ao tratamento sem compactação adicional e aquele com duas passadas de máquina. Quando comparados esses dois últimos tratamentos, a diferença na resistência foi sempre inferior a $500 \mathrm{kPa}$. Com quatro passadas, o maior valor de resistência $(3.800 \mathrm{kPa})$ ocorreu na profundidade de $11 \mathrm{~cm}$, enquanto, com duas passadas, o maior valor $(2.250 \mathrm{kPa})$ foi a $6 \mathrm{~cm}$.

Esses resultados confirmam as afirmações de STRECK et al. (2004) ao sugerirem que a pressão exercida pelo tráfego de duas passadas não tenha se transferido em profundidade, devido à compactação observada abaixo da profundidade de $7 \mathrm{~cm}$, confinando as pressões na camada superficial.

Portanto, o equipamento desenvolvido permitiu a avaliação da variação espacial e temporal da resistência mecânica do solo à penetração, seja devida a características morfológicas naturais do perfil, seja induzidas pelo uso e manejo do solo.

\section{CONCLUSÕES}

No equipamento desenvolvido e testado, a quantificação da resistência é realizada com célula de carga, a distância de penetração no solo com potenciômetro e a aquisição e o armazenamento de dados com placas eletrônicas.

A concepção do equipamento, que emprega velocidade constante de penetração da haste no perfil do solo, possibilitou a aquisição de grande coleção de dados relativos à pequena variação de profundidade $(5 \mathrm{~mm})$ e atingindo a profundidade máxima de $0,80 \mathrm{~m}$. 
O equipamento é eficaz na aquisição e no tratamento de dados de resistência mecânica do solo à penetração em profundidade do perfil.

A variação entre os pontos permite inferir sobre parâmetros e características do solo, bem como sobre o comportamento desses sob condições externas impostas, quer seja imediata, quer seja residual.

\section{REFERÊNCIAS}

ALBUQUERQUE, J.A.; REINERT, D.J.; FIORIN, J.E. Variabilidade de solo e planta em Podzólico Vermelho-Amarelo. Revista Brasileira de Ciência do Solo, Viçosa, v.20, n.1, p.151-7, 1996.

ARRIAGA, F.J.; REINERT, D.J.; LOWERY, B.; MCSWEENY. Development of threedimensional maps of eroded soil with data from a profile cone penetrometer. In: WORLD CONGRESS OF SOIL SCIENCE, 17., 2002, Bangkok. Proceedings... Bangkok: ISSS, 2002. v.1, p.1-8.

ASAE. AMERICAN SOCIETY OF AGRICULTURAL ENGINEERS. Procedures for using and reporting data obtained with the soil cone penetrometer. St Joseph, 1999. p.964-6. (ASAE standard: ASAE EP542)

BRADFORD, J.M. Penetrability. In: KLUTE, A. Methods of soil analysis. Madison: ASA, 1986. part 1, p.463-78.

KLEIN, V.A.; LIBARDI, P.L. A faixa de umidade menos limitante ao crescimento vegetal e a sua relação com a densidade do solo ao longo de um perfil de um Latossolo Roxo. Ciência Rural, Santa Maria, v.30, n.6, p.959-64,2000.

LARNEY, F.J.; HUFFMAN, R.L.; SCHULER, R.T.; TAYLOR, D.R.; KLADIVKO, E.J.; LOWERY, B. A portable, self-leveling, constant-rate cone penetrometer with cone penetrometer with computer-controlled data acquisition for tillage studies. Soil \& Tillage Research, Amsterdam, v.14, p.231-9, 1989.

LETEY, J. Relationship between soil physical properties and crop production. Advances in Soil Science, New York, v.1, n.2, p.277-94,1985.

LOWERY, B. A portable constant-rate cone penetrometer. Soil Science Society of American Journal, Madison, v.50, p.412-4,1986.

LOWERY, B.; MORRISON, J.E. Soil penetrometers and penetrability. In: DANE, J.H.; TOPP, G.C. Methods of soil analysis. Madison: Soil Science Society of America, 2002. p.363-88.

PERUMPRAL, J.V. Cone penetrometer applications - a review. Transactions of the ASAE, St. Joseph, v.30, n.4, p.939-44,1987.

REINERT, D.J.; REICHERT, J.M.; SILVA, V.R. Propriedades físicas de solos em sistema plantio direto irrigado. In: CARLESSO, R.; PETRY, M. T.; ROSA, G. M.; CERETTA, C. Irrigação por aspersão no Rio Grande do Sul. Santa Maria: Palloti, 2001a. p.114-33.

REINERT, D.J.; WOLKOWSKI, R.P.; LOWERY, B.; ARRIAGA, F.J. Compaction effects on plant water use. 2001b. In: WISCONSIN FERTILIZER, AGLIME \& PEST MANAGEMENT CONFERENCE, 2001, Madison. Anais... Madison: University of Wisconsin-Extension, 2001b. v.40, p.222-32.

ROONEY, D.J.; LOWERY, B. A profile cone penetrometer for mapping soil horizons. Soil Science Society of American Journal, Madison, v.64, n.6, p.2136-9, 2000.

SCHULER, R.T.; LOWERY, B. A self-leveling portable constant rate penetrometer. St. Joseph: ASAE, 1987. 8 p. (Paper 87-1520). 
SILVA, A.P.; KAY, B.D.; PERFECT, E. Characterization of the least limiting water range of soils. Soil Science Society of American Journal, Madison, v.58, n.6, p.1775-81,1994.

STRECK, C.A.; REINERT, D. J.; REICHERT, J.M.; KAISER, D.R. Modificações de propriedades físicas com a compactação do solo causada pelo tráfego induzido de um trator em plantio direto.

Ciência Rural, Santa Maria, v.34, n.3, p.755-60, 2004.

TAYLOR, H.M.; GARDNER, H.R. Penetration of cotton seedling taproots as influenced by bulk density, moisture content and strength of soil. Soil Science, Baltimore, v.96, p.153-6,1963.

TAYLOR, H.M.; ROBERSON, G.M.; PARKER, J.J. Soil strength-root penetration relations for medium- to coarse-textured soil materials. Soil Science, Baltimore, v.102, n.1, p.18-22,1966.

THOMPSON, P.J.; JANSEN, I.J.; KOOKS, C.L. Penetrometer resistance and bulk density as parameters for predicting root system performance in mine soils. Soil Science Society of American Journal, Madison, v.51, p.1288-93,1987.

UNIMEASURE. LX-PA series ratiometric voltage output. Disponível em: www.unimeasure.com/obj--pdf/pdf-lx-pa.pdf. Acesso em: 17 abr. 2007.

WILFORD, J.R.; WOOTEN, O.B.; EUGHAM, F.E. Tractor mounted field penetrometer. Transactions of the ASAE, St Joseph, v.15, p.226-7,1972. 